\title{
Long-term disability in anxiety disorders
}

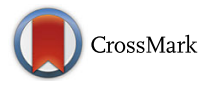

\author{
Sanne M. Hendriks ${ }^{*}$, Jan Spijker ${ }^{2}$, Carmilla M. M. Licht ${ }^{3}$, Florian Hardeveld ${ }^{4}$, Ron de Graaf ${ }^{5}$, Neeltje M. Batelaan ${ }^{3}$, \\ Brenda W. J. H. Penninx ${ }^{3}$ and Aartjan T. F. Beekman ${ }^{3}$
}

\begin{abstract}
Background: This longitudinal study aims to investigate differences in long-term disability between social anxiety disorder (SAD), panic disorder with agoraphobia (PDA), panic disorder without agoraphobia (PD), generalized anxiety disorder (GAD) and multiple anxiety disorders (multiple $A D$ ), focusing on the effects of different course trajectories (remission, recurrence and chronic course) and specific symptom dimensions (anxiety arousal and avoidance behaviour).

Methods: Data were used from participants with no psychiatric diagnosis (healthy controls, $n=647$ ) or with a current anxiety disorder (SAD, $n=191 ; \mathrm{PDA}, n=90 ; \mathrm{PD}, n=84 ; \mathrm{GAD}, n=110$; multiple $A D, n=480$ ). Severity of anxiety arousal and avoidance behaviour symptoms was measured using the Beck Anxiety Inventory and the Fear Questionnaire. The World Health Organization Disability Assessment Schedule II was used to measure disability.

Results: Long-term disability was most prevalent in participants with SAD and multiple AD, and lowest in PDA and PD. GAD had an intermediate position. Anxiety arousal and avoidance behaviour were associated with more long-term disability in anxiety disorders than course trajectories.

Conclusions: Various anxiety disorders have different disability levels over 4 years of time, therefore diagnostic distinction is important for treatment focus. Anxiety arousal and avoidance behaviour are major predictors for long-term disability in anxiety disorders.
\end{abstract}

\section{Background}

Disability is often defined as 'any restriction or lack of capacity to perform an activity in a manner or within a range considered normal for a human being' [1]. Anxiety disorders are associated with severe disability [2-6] and the negative impact of anxiety is substantial $[3,7,8]$. Previous research showed that anxiety disorders differ in disability levels. Overall, multiple anxiety disorders (multiple $\mathrm{AD}$, i.e. comorbidity with other anxiety disorders) are associated with more disability than pure anxiety disorders [9]. Furthermore, social anxiety disorder (SAD) and generalized anxiety disorder (GAD) are associated with higher disability levels compared to panic disorder, $[3,10-12]$ although other research points out otherwise [13-15]. However, it remains unclear whether contrasts

\footnotetext{
* Correspondence: s.hendriks@propersona.nl

${ }^{1}$ Department of Psychiatry, Pro Persona Mental Health Care, Zandstraat 54, Veenendaal 3905 ED, The Netherlands

Full list of author information is available at the end of the article
}

in disability levels among anxiety disorders persist over a longer period.

More severe symptoms and more comorbidity are associated with a chronic course in anxiety disorders [16-20]. Therefore, we expect that long-term disability is more common in anxiety patients with a chronic course. However, some research gave indications that disability can still be present after remission of the anxiety disorder [21]. Because $\mathrm{SAD}$ and multiple $\mathrm{AD}$ are more strongly associated with a chronic course than other anxiety disorders $[19,22-24]$ we expect that long-term disability therefore is more prevalent in SAD and multiple AD.

Furthermore, previous research showed that symptom dimensions, like anxiety arousal and avoidance behaviour, can be strong predictors [19, 20, 25]. Hendriks et al. [19] showed that avoidance behaviour symptoms may be more important predictors than the symptoms of anxiety itself. This would lead to the hypothesis that long-term disability is more frequently seen in panic disorder with agoraphobia (PDA) and SAD compared to panic disorder without agoraphobia (PD) and GAD because of the high levels of avoidance behaviour in PDA and SAD. 
This longitudinal study among a large cohort of participants with anxiety disorders investigates: 1) differences in long-term disability between participants with social anxiety disorder (SAD), panic disorder with agoraphobia (PDA), panic disorder without agoraphobia (PD), generalized anxiety disorder (GAD) and multiple anxiety disorders (multiple AD); 2) differences in long-term disability for different course trajectories; and 3) the role of anxiety arousal and avoidance behaviour in long-term disability.

\section{Methods}

\section{Study sample}

As reported before, [11, 19, 20]. The Netherlands Study of Depression and Anxiety (NESDA) is a naturalistic cohort study to examine the long-term course and consequences of anxiety and depressive disorders [26]. In short, a total of 2981 participants were included, aged 18 through 65 years. The research protocol was approved centrally by the ethical review board of VU University Medical Center. Subsequently it was approved by the local ethical review boards of Leiden University Medical Center and University Medical Center Groningen. The study was performed in accordance with the ethical standards of the Declaration of Helsinki. All participants provided written informed consent. Participants with a current or lifetime diagnosis of anxiety or depression, and healthy controls were included. Exclusion criteria were (1) a primary diagnosis of psychotic, obsessive compulsive, bipolar or severe addiction disorder, and (2) not being fluent in Dutch.

Participants with an anxiety disorder (SAD, PDA, PD, GAD and multiple AD) at baseline (6-month recency diagnosis) and healthy controls were included for this study (Fig. 1). A follow-up assessment was done two (T1) and 4 years (T2) after the baseline measurement. In total 1602 participants met these criteria at T0 (baseline); 191 participants (11.9\%) with pure SAD, 90 participants (5.6 \%) with pure PDA, 84 participants (5.2\%) with pure PD, 110 participants (6.9\%) with pure GAD, 480 participants (30.0\%) with multiple AD and 647 healthy controls (40.4\%). 1351 participants (84.3\%) had a follow-up assessment at T1, and 1235 participants $(77.1 \%)$ at T2.

\section{Psychiatric status}

As done before, $[11,19,20]$ the Composite International Diagnostic Interview (CIDI version 2.1) was used to diagnose the presence of SAD, PDA, PD, GAD and multiple $\mathrm{AD}$, a highly reliable and valid instrument for assessing anxiety disorders [27].

\section{Course trajectory}

The clinical course trajectory categorized the participants into four groups: a) healthy controls (no history of anxiety disorder and no anxiety disorder at T0, T1 and T2), b) remission (remission of baseline anxiety disorder at $\mathrm{T} 1 \mathrm{and} /$ or T2 without recurrence), c) recurrence (remission of baseline anxiety disorder at $\mathrm{T} 1$ but with recurrence at $\mathrm{T} 2$ ), and d) chronic course (baseline anxiety disorder at T0, T1 and T2).

\section{Anxiety arousal and avoidance behaviour}

As done before, $[11,19,20]$ the Beck Anxiety Inventory (BAI) [28] and the Fear Questionnaire (Fear Q) [29]

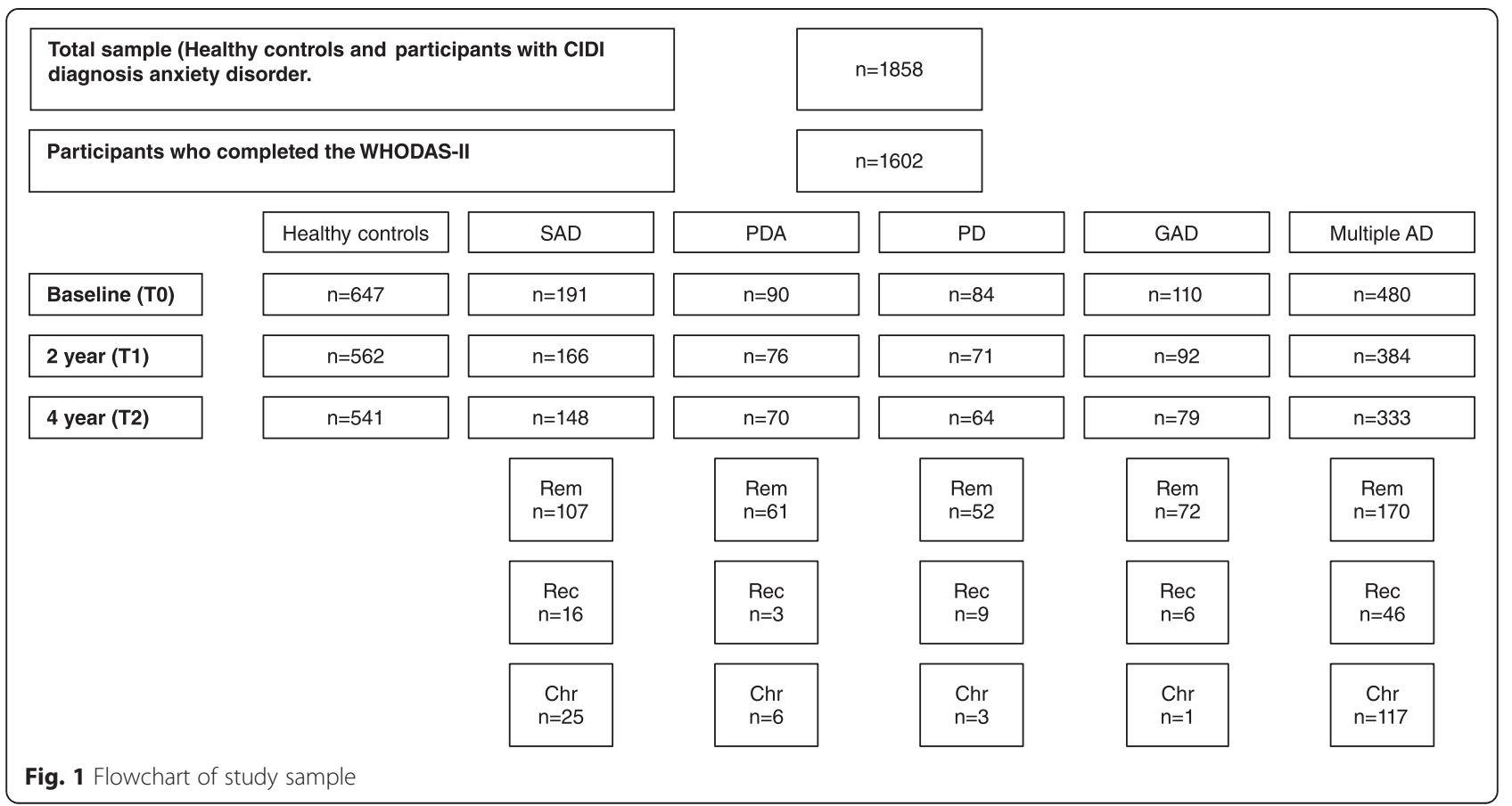


were used to measure baseline severity of anxiety arousal and avoidance behaviour symptoms, respectively. The BAI and the Fear Q are both widely used and have proven to be highly valid and reliable [30,31]. The Cronbach's $\alpha$ in this study for the BAI and the Fear Q were .94 and .89 , respectively.

\section{Disability}

To measure disability at baseline, after two and after 4 years, we used the total score of the World Health Organization Disability Assessment Schedule II.(WHODAS-II) [32]. The WHODAS-II provides a functioning profile for six activity domains (cognition, mobility, selfcare, social interaction, life activities and participation). To measure general disability, domain scores were combined into a total score. The WHODAS-II shows good inter-item reliability with a Cronbach's $\alpha$ of .96 for the total score. In Hendriks et al. [11] a cross sectional study was conducted to compare the different disability domains of the WHODAS-II between different anxiety disorders and healthy controls. The results showed that disability was generally highest in multiple anxiety disorder (e.g. mean disability in cognition $=33.7$ ) and social anxiety disorder $($ mean $=32.7)$, followed by generalized anxiety disorder (mean $=27.2)$ and panic disorder with agoraphobia $($ mean $=26.3$ ), and lowest in panic disorder without agoraphobia $($ mean $=22.1)$. This pattern was consistently present across different disability domains, therefore for this study we choose to use only the total score of the WHODAS-II.

\section{Covariates}

As done before, [11] covariates at baseline were set: age, gender, years of education attained, partner status, number of somatic illnesses and comorbid depressive disorder. Previous studies showed that these covariates are associated with both anxiety and disability [33, 34].

\section{Statistical analyses}

SPSS Version 20.0 (SPSS Inc, Chicago, Illinois) was used for the statistical analyses. We used chi-square statistics for categorical and analyses of variance for continuous variables to compare sociodemographic, clinical psychiatric characteristics and long-term disability between healthy controls and participants with anxiety disorders. Linear mixed models (LMM) [35] were used to analyse the relationship between 1) baseline psychiatric status, 2) course trajectories and 3) symptom dimensions with the outcome long-term disability.

\section{Results}

Table 1 presents the demographic and clinical characteristics of the total sample. A chronic course was most prevalent in the multiple AD group (35.1\%). After 4 years
$64.9 \%$ of the participants with SAD, $68.6 \%$ of PDA, $65.6 \%$ of PD, $79.7 \%$ of GAD and $51.1 \%$ of multiple $\mathrm{AD}$ were without an anxiety disorder $\left(X^{2}=355.5, \mathrm{df}=25, p<.001\right)$. Anxiety arousal and avoidance behaviour symptoms were highest in the multiple $\mathrm{AD}$ group compared to other groups (BAI $\mathrm{F}=286.2, \mathrm{df}=5, p<.001$; Fear $\mathrm{Q} F=205.12$, $\mathrm{df}=5, p<.001)$.

Figure 2 shows 4-year disability patterns between participants with SAD, PDA, PD, GAD, multiple AD and healthy controls $(n=1235)$ at each time point. Healthy controls experienced less disability compared to participants with any anxiety disorder and this differed significantly at baseline (all $p$-values $<.001$ ), 2-year follow-up (all $p$-values $<.05$ ) and 4 -year follow-up (all $p$-values $<.04$ ). Generally, SAD and multiple AD participants experienced most disability. Disability was lowest in PDA and PD, and GAD had an intermediate position. At baseline, participants with SAD, GAD and multiple $\mathrm{AD}$ experienced more disability than participants with PDA and PD (all $p$-values $<.03$ ). Participants with multiple $\mathrm{AD}$ had more disability than participants with $\mathrm{PD}$ at 2 years (T1) $(p=.01)$. At 4 years (T2), participants with SAD showed more disability than participants with PDA $(p=.02)$, and participants with multiple $\mathrm{AD}$ showed more disability than participants with $\mathrm{PD}(p=.01)$ and PDA $(p=.02)$.

Table 2 shows LMM analyses for long-term disability. Univariable analyses indicate that having an anxiety disorder at baseline predicts long-term disability. SAD x time, PDA $x$ time, GAD $x$ time and multiple AD $x$ time showed significant negative associations. This indicates that during follow-up the impact of the disorders on long-term disability became smaller. Course trajectories (remission, recurrence and chronic course) and symptom dimensions (anxiety arousal and avoidance behaviour) were also associated with long-term disability. No associations were found for symptom dimensions $\mathrm{x}$ time, suggesting that associations did not significantly change over time.

In Model 1 the degree was examined to which course trajectories contribute to long-term disability across anxiety disorders. Baseline psychiatric status and chronic course remained significant predictors. Also SAD x time, PDA $x$ time, GAD $x$ time and multiple $\mathrm{AD} \times$ time remained significant. This indicates that during follow-up the impact of baseline SAD, PDA, GAD and multiple AD on long-term disability became smaller.

In Model 2 baseline psychiatric status and symptom dimensions were assessed together. The results show that all coefficients decreased notably and only SAD, GAD, multiple $\mathrm{AD}$, anxiety arousal and avoidance behaviour remained significant. PDA and PD did not remain significant. This indicates that anxiety arousal and avoidance behaviour lead to more long-term disability in anxiety disorders, which especially explain the found disability levels in PD and PDA. 
Table 1 Demographic and clinical characteristics of the total sample (healthy controls and participants with different anxiety disorders, $n=1602$ )

\begin{tabular}{|c|c|c|c|c|c|c|c|}
\hline & Healthy controls & SAD & PDA & PD & GAD & Multiple AD & $p^{a}$ \\
\hline & $n=647$ & $n=191$ & $n=90$ & $n=84$ & $n=110$ & $n=480$ & \\
\hline \multicolumn{8}{|l|}{ Sociodemographics } \\
\hline Age (mean, SD) & $41.1(14.6)$ & $37.3(11.9)$ & $40.1(12.5)$ & $38.3(11.1)$ & $37.4(12.0)$ & $40.8(11.7)$ & .001 \\
\hline Sex (\% female) & 61.7 & 64.9 & 74.4 & 59.5 & 69.1 & 68.5 & .05 \\
\hline Education (mean, SD) & $12.8(3.2)$ & $12.6(3.2)$ & $12.1(3.4)$ & $12.4(3.1)$ & $12.4(3.1)$ & $11.3(3.3)$ & $<.001$ \\
\hline Partner status (\% yes) & 75.0 & 56.5 & 70.0 & 73.8 & 70.0 & 63.8 & $<.001$ \\
\hline \multicolumn{8}{|l|}{ Clinical psychiatric characteristics } \\
\hline Number of somatic illnesses (mean, SD) & $0.7(1.0)$ & $0.8(0.9)$ & $0.9(1.0)$ & $0.7(0.8)$ & $0.7(0.9)$ & $1.1(1.2)$ & $<.001$ \\
\hline Comorbid depressive disorder (\%) & 0 & 41.9 & 38.7 & 40.5 & 62.7 & 72.5 & $<.001$ \\
\hline Psychiatric course trajectories (\%) & & & & & & & $<.001$ \\
\hline Remission & - & 72.3 & 87.1 & 81.2 & 91.1 & 51.1 & \\
\hline Recurrence & - & 10.8 & 4.3 & 14.1 & 7.6 & 13.8 & \\
\hline Chronic course & - & 16.9 & 8.6 & 4.7 & 1.3 & 35.1 & \\
\hline Psychiatric status after 4 years (\%) & & & & & & & $<.001$ \\
\hline No anxiety disorder & - & 64.9 & 68.6 & 65.6 & 79.7 & 51.1 & \\
\hline Social anxiety disorder & - & 20.9 & 2.9 & 3.1 & 7.6 & 16.8 & \\
\hline Panic disorder with agoraphobia & - & 0 & 8.6 & 4.7 & 0 & 6.3 & \\
\hline Panic disorder without agoraphobia & - & 2.0 & 8.6 & 12.5 & 3.8 & 6.3 & \\
\hline Generalized anxiety disorder & - & 4.1 & 5.7 & 1.6 & 8.9 & 7.2 & \\
\hline Multiple anxiety disorder & - & 8.1 & 5.7 & 12.5 & 0 & 12.3 & \\
\hline \multicolumn{8}{|l|}{ Symptom dimensions } \\
\hline Anxiety arousal (BAl, mean, SD) & $4.1(4.9)$ & $13.9(9.1)$ & $19.1(11.6)$ & $14.2(8.9)$ & $14.6(8.2)$ & $23.1(11.1)$ & $<.001$ \\
\hline Avoidance behaviour (Fear Q, mean, SD) & $12.1(12.2)$ & $34.4(18.8)$ & $32.1(19.0)$ & $22.8(18.1)$ & $25.0(16.3)$ & $43.7(20.6)$ & $<.001$ \\
\hline
\end{tabular}

${ }^{a} p$-value based on chi-square statistics for categorical variables and analyses of variances for continuous variables

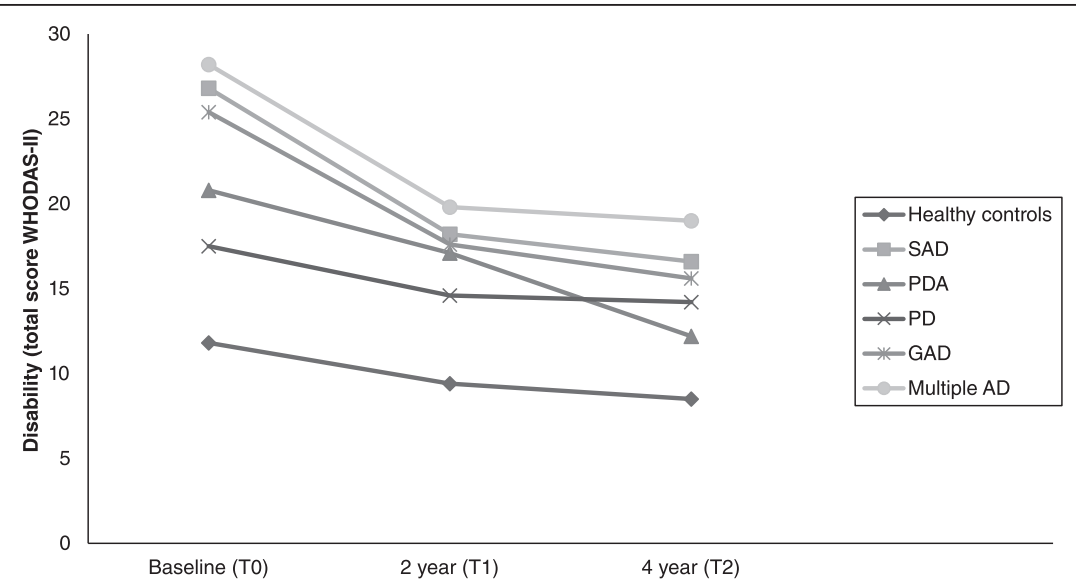

* based on analyses of variances, corrected for covariatesage, sex, education, partner status, number of somatic illnessesandcomorbid depression

Fig. 2 Disability (total score WHODAS-II) over 4 years of time for baseline psychiatric status $(n=1235)$ * 
Table 2 Linear mixed model analyses for long-term disability (total score WHODAS-II)

\begin{tabular}{|c|c|c|c|c|c|c|c|c|}
\hline & \multicolumn{8}{|l|}{ Disability } \\
\hline & \multicolumn{2}{|l|}{ Univariable } & \multicolumn{2}{|l|}{ Model 1} & \multicolumn{2}{|l|}{ Model 2} & \multicolumn{2}{|l|}{ Model 3} \\
\hline & $\overline{B(S E)}$ & $p$ & $B(S E)$ & $p$ & $B(S E)$ & $p$ & $B(S E)$ & $p$ \\
\hline \multicolumn{9}{|l|}{ Baseline psychiatric status } \\
\hline Healthy controls & Ref & & Ref & & Ref & & Ref & \\
\hline SAD & $15.28(1.55)$ & $<.001$ & $14.26(1.74)$ & $<.001$ & $5.09(1.42)$ & $<.001$ & $4.38(1.55)$ & $<.001$ \\
\hline SAD $\times$ time & $-6.48(0.61)$ & $<.001$ & $-6.40(0.61)$ & $<.001$ & $-2.52(0.57)$ & .01 & $-2.56(0.57)$ & .01 \\
\hline PDA & $9.31(2.09)$ & $<.001$ & $9.54(2.24)$ & $<.001$ & $-0.46(1.88)$ & .65 & $-0.65(1.98)$ & .52 \\
\hline PDA $\times$ time & $-4.18(0.85)$ & $<.001$ & $-4.04(0.85)$ & $<.001$ & $-0.07(0.77)$ & .94 & $-0.11(0.77)$ & .92 \\
\hline PD & $5.96(2.15)$ & $<.001$ & $6.40(2.29)$ & $<.001$ & $0.46(1.84)$ & .65 & $0.23(1.94)$ & .82 \\
\hline PD $\times$ time & $-1.43(0.88)$ & .15 & $-1.29(0.88)$ & .20 & $-0.07(0.77)$ & .95 & $-0.11(0.77)$ & .92 \\
\hline GAD & $13.01(1.93)$ & $<.001$ & $13.19(2.07)$ & $<.001$ & $6.62(1.68)$ & $<.001$ & $6.07(1.77)$ & $<.001$ \\
\hline GAD $\times$ time & $-5.80(0.79)$ & $<.001$ & $-5.58(0.80)$ & $<.001$ & $-3.52(0.70)$ & $<.001$ & $-3.55(0.70)$ & $<.001$ \\
\hline Multiple AD & $20.93(1.57)$ & $<.001$ & $18.21(1.58)$ & $<.001$ & $3.58(1.46)$ & $<.001$ & $3.00(1.58)$ & .003 \\
\hline Multiple AD x time & $-7.61(0.54)$ & $<.001$ & $-7.54(0.54)$ & $<.001$ & $-1.31(0.58)$ & .19 & $-1.36(0.58)$ & .18 \\
\hline \multicolumn{9}{|l|}{ Psychiatric course trajectory } \\
\hline Healthy controls & Ref & & Ref & & & & Ref & \\
\hline Remission & $10.30(0.82)$ & $<.001$ & $-3.12(1.12)$ & .002 & & & $0.63(0.84)$ & .53 \\
\hline Recurrence & $7.82(1.66)$ & $<.001$ & $-0.01(1.70)$ & .99 & & & $0.42(1.23)$ & .67 \\
\hline Chronic course & $14.65(1.32)$ & $<.001$ & $3.65(1.48)$ & $<.001$ & & & $0.94(1.08)$ & .35 \\
\hline \multicolumn{9}{|l|}{ Symptom dimensions } \\
\hline Anxiety arousal & $24.28(0.04)$ & $<.001$ & & & $12.49(0.06)$ & $<.001$ & $12.51(0.06)$ & $<.001$ \\
\hline Anxiety arousal $x$ time & $1.49(0.02)$ & .14 & & & $0.90(0.03)$ & .37 & $0.86(0.03)$ & .39 \\
\hline Avoidance behaviour & $23.28(0.02)$ & $<.001$ & & & $10.58(0.03)$ & $<.001$ & $10.57(0.03)$ & $<.001$ \\
\hline Avoidance behaviour $x$ time & $-1.40(0.01)$ & .16 & & & $0.17(0.01)$ & .87 & $0.14(0.01)$ & .89 \\
\hline
\end{tabular}

${ }^{a}$ Analyses corrected for covariates age, sex, education, partner status, number of somatic illnesses and comorbid depression

Model 1: baseline psychiatric status and course trajectories; Model 2: baseline psychiatric status and symptom dimensions; Model 3: final model

In Model 3, baseline psychiatric status, course trajectories and symptom dimensions were assessed together. $\mathrm{SAD}$, GAD, multiple AD, anxiety arousal and avoidance behaviour remained significant but course trajectories not. Furthermore, SAD $x$ time and GAD $x$ time remained significant. This indicates that the impact of SAD and GAD on long-term disability remained irrespective of course and symptom dimensions.

\section{Discussion}

The results showed that all anxiety disorders were associated with more disability over 4 years of time compared to healthy controls, though differences became smaller over time.

Long-term disability was most prevalent in participants with SAD and multiple AD, and lowest in PDA and PD. GAD had an intermediate position. Furthermore, we found differences between course trajectories; a chronic course predicts long-term disability better than remission and recurrence. However, symptom dimensions seem to be stronger predictors of long-term disability than course trajectories.

Our finding that long-term disability is more prevalent in SAD and multiple AD compared to other anxiety disorders, is in line with previous results [36, 37] Because SAD and multiple $\mathrm{AD}$ are more associated with a chronic course than other anxiety disorders $[20,22,23]$ and a chronic course is associated with more disability, [21] we expected that long-term disability is more prevalent in SAD and multiple AD. Our results showed that a chronic course is indeed associated with long-term disability. Avoidance behaviour was also associated with long-term disability in our study. We hypothesised that long-term disability would be high in SAD, PDA and multiple AD because of the high levels of avoidance behaviour in these disorder. However, PDA had a low position. So the assumption that avoidance behaviour predicts long-term disability better than anxiety arousal seems to be debatable.

Our findings showed intermediate associations for long-term disability and GAD. The association between GAD and disability may be particularly strong because 
worry is pervasive and can be focused on any area (more general concerns, including social situations and physical concerns), whereas the focus of distress for SAD, PDA and PD is more narrow. Nevertheless, this finding is only partly in line with previous results. Naragon-Gainey et al. [12] found that GAD at baseline was more associated with severe disability in certain areas (i.e. work, household, family, private leisure) compared to SAD and PDA/PD. However, after 2 years participants with GAD at baseline experienced no more disability than participants with SAD and PDA/PD. Previous research showed that comorbidity between GAD and other mental disorders is high (e.g. major depressive disorder) [5, 38-41]. Possibly, this high comorbidity can explain the inconsistent results among previous research. However, other research pointed out that the disability seen in GAD cannot be explained by comorbidity [42].

The results showed that long-term disability is lowest in PDA and PD which is partly in line with other studies $[12,13]$. As mentioned in our previous study [11], disability in PDA and PD is generally associated with physical disability [14, 37]. Unfortunately, physical disability is not measured by the WHODAS-II very well and we can therefore not establish whether PDA and PD participants in this study have more physical disability compared to other participants.

Baseline psychiatric status and symptom dimensions were stronger predictors for long-term disability than course trajectories. This indicates that participants with SAD, GAD and multiple AD remain more disabled than PDA and PD, despite the course. Furthermore, although remission rates were relatively high, participants with anxiety disorders at baseline remain more disabled than healthy controls after 4 years. Possibly, baseline psychiatric status contains important information which was not measured in our study, such as age of onset, environmental factors, personality characteristics, and premorbid functioning. Another possibility is that when participants remit over 4 years, subthreshold anxiety symptoms may still be present and cause disability. Previous research indeed showed that subthreshold anxiety is also associated with long-term disability $[43,44]$.

This study has several strengths. Adequate analyses were performed because of the structured psychiatric interview, the large representative sample, and the longitudinal design. LMM analyses made it possible that all available information was used, even from participants with partly missing data. This study has also limitations. First, not all anxiety disorders are included in NESDA (e.g., obsessive compulsive disorder, posttraumatic stress disorder and specific phobia). However, in this study DSM-IV diagnoses were used instead of DSM-5. In DSM-5 obsessive compulsive disorder and posttraumatic stress disorder do not belong to the anxiety disorders chapter anymore and are discussed in separate chapters. Next, participants with depressive disorders were not excluded but analyses were corrected for comorbid depression. Furthermore, there can be differences in disability in the duration of a chronic disorder. For example, having a chronic anxiety disorder for 20 years causes possibly a different level of disability than having a chronic anxiety disorder for 5 years.

\section{Conclusions}

Generally, long-term disability was highest in participants with SAD and multiple AD, followed by participants with GAD, and lowest in participants with PDA and PD. This means that various anxiety disorders have different disability levels over 4 years of time, so diagnostic distinction is important for treatment focus. When there is more than one anxiety disorder present there must be examined which anxiety symptoms are the most severe and disabling for the patient so treatment can focus on these symptoms. Our results show that anxiety arousal and avoidance behaviour lead to more long-term disability in anxiety disorders compared to course trajectories. Taken together, symptom dimensions in anxiety disorders give important information about disability over time. The use of symptom dimensions could eventually give more insight in all the complex associations in psychopathology and determine how psychiatric problems develop over time. The efficacy of transdiagnostic interventions for anxiety disorder patients (e.g. acceptance and commitment therapy and cognitive behavioural therapy) which are targeting these underlying processes might be evaluated or new interventions can be developed in order to prevent long-term disability. The results of our studies support the concepts of the DSM-5, which includes dimensional aspects of diagnosis along with categories.

\section{Acknowledgements \\ The infrastructure for the NESDA study (www.nesda.nl) is funded through the Geestkracht program of the Netherlands Organisation for Health Research and Development (zon-Mw, grant number 10-000-1002) and is supported by participating universities and mental health care organisations (VU University Medical Center, GGZ inGeest, Arkin, Leiden University Medical Center, GGZ Rivierduinen, University Medical Center Groningen, Lentis, GGZ Friesland, GGZ Drenthe, Scientific Institute for Quality of Healthcare (IQ healthcare), Netherlands Institute for Health Services Research (NIVEL) and Netherlands Institute of Mental Health and Addiction (Trimbos Institute)).}

\section{Availability of data and materials \\ The data of NESDA will not be made available in order to protect the participant's identity.}

\section{Authors' contributions}

$A B$ and BP designed the Netherlands Study of Depression and Anxiety and wrote the protocol. SH designed the analysis plan, managed the literature searches and analyses, and wrote the manuscript. $\mathrm{CL}$ contributed to the statistical analyses. SH, JS, CL, FH, RG, NB, BP and AB had full access to all of the data in the study and take responsibility for the integrity of the data and the accuracy of the data analysis. SH, JS, CL, FH, RG, NB, BP and AB critically revised the manuscript. $\mathrm{SH}, J \mathrm{~S}, \mathrm{CL}, \mathrm{FH}, \mathrm{RG}, \mathrm{NB}, \mathrm{BP}$ and $\mathrm{AB}$ read and approved the final manuscript. 


\section{Competing interests}

On behalf of all authors, the corresponding author states that there are no competing interests.

\section{Consent for publication \\ Non applicable.}

\section{Ethics approval and consent to participate}

The research protocol was approved centrally by the ethical review board of VU University Medical Center. Subsequently it was approved by the local ethical review boards of Leiden University Medical Center and University Medical Center Groningen. The study was performed in accordance with the ethical standards of the Declaration of Helsinki. All participants provided written informed consent.

\begin{abstract}
Author details
${ }^{1}$ Department of Psychiatry, Pro Persona Mental Health Care, Zandstraat 54, Veenendaal 3905 ED, The Netherlands. ${ }^{2}$ Pro Persona Mental Health Care, Radboud University Nijmegen, Reinier Postlaan 6, Nijmegen 6525 GC, The Netherlands. ${ }^{3}$ Department of Psychiatry/EMGO Institute, VU University Medical Center, AJ Ernststraat 887, Amsterdam 1081 HL, The Netherlands. ${ }^{4}$ Pro Persona Mental Health Care, Willy Brandtlaan 20, Ede 6717 RR, The Netherlands. ${ }^{5}$ Netherlands Institute of Mental Health and Addiction, Da Costakade 45, Utrecht 3521 VS, The Netherlands.
\end{abstract}

\section{Received: 2 September 2015 Accepted: 24 June 2016}

\section{Published online: 19 July 2016}

\section{References}

1. Sherbourne CD, Wells KB, Meredith LS, Jackson CA, Camp P. Comorbid anxiety disorders and the functioning and well-being of chronically ill patients of general medical providers. Arch Gen Psychiatry. 1996;53:889-94.

2. Alonso J, Angermeyer MC, Bernert S, Bruffaerts R, Brugha TS, Bryson H, et al. Disability and quality of life impact of mental disorders in Europe: results from the European Study of the Epidemiology of Mental Disorders (ESEMeD) project. Acta Psychiatr Scand Suppl. 2004;420:38-46.

3. Bijl RV, Ravelli A. Current and residual functional disability associated with psychopathology: findings from the Netherlands Mental Health Survey and Incidence Study (NEMESIS). Psychol Med. 2000;30:657-68.

4. Stein MB, Roy-Byrne PP, Craske MG, Bystritsky A, Sullivan G, Pyne JM, et al. Functional impact and health utility of anxiety disorders in primary care outpatients. Med Care. 2005;43:1164-70.

5. Olfson M, Fireman B, Weissman MM, Leon AC, Sheehan DV, Kathol RG, et al. Mental Disorders and disability among patients in a primary care group practice. Am J Psychiatry. 1997;154:1734-40.

6. Mendlowicz MV, Stein MB. Quality of life in individuals with anxiety disorders. Am J Psychiatry. 2000;157:669-82.

7. Norberg MM, Diefenbach GJ, Tolin DF. Quality of life and anxiety and depressive disorder comorbidity. J Anxiety Disord. 2008;22:1516-22.

8. Henning ER, Turk CL, Mennin DS, Fresco DM, Heimberg RG. Impairment and quality of life in individuals with generalized anxiety disorder. Depress Anxiety. 2007;24:342-9

9. World Health Organization. International Classification of Impairments, Disabilities and Handicaps. Geneva: World Health Organization; 1980.

10. Comer JS, Blanco C, Hasin DS, Liu S, Grant BF, Turner B, et al. Health-related quality of life across the anxiety disorders: results from the National Epidemiologic Survey on alcohol and related conditions (NESARC). J Clin Psychiatry. 2011;72:43-50.

11. Hendriks SM, Spijker J, Licht CMM, Beekman ATF, Hardeveld F, de Graaf R, et al. Disability in anxiety disorders. J Affect Disord. 2014;166:227-33.

12. Naragon-Gainey K, Gallagher MW, Brown TA. A longitudinal examination of psychosocial impairment across the anxiety disorders. Psychol Med. 2014;44:1691-700

13. Sherbourne C, Sullivan G, Craske MG, Roy-Byrne P, Golinelli D, Rose RD, et al. Functioning and disability levels in primary care outpatients with one or more anxiety disorders. Psychol Med. 2010;40:2059-68.

14. Schonfeld WH, Verboncoeur CJ, Fifer SK, Lipschutz RC, Lubeck DP Buesching DP. The functioning and well-being of patients with unrecognized anxiety disorders and major depressive disorder. J Affect Disord. 1997;43:105-19.
15. Olatunji BO, Cisler JM, Tolin DF. Quality of life in anxiety disorders: A metaanalytic review. Clin Psychol Rev. 2007;27:572-81.

16. Fichter MM, Quadflieg N, Fischer UC, Kohlboeck G. Twenty-five-year course and outcome in anxiety and depression in the Upper Bavarian Longitudinal Community Study. Acta Psychiatr Scand. 2010;122:75-85.

17. Merikangas KR, Zhang H, Avenevoli S, Acharyya S, Neuenschwander M, Angst J. Longitudinal trajectories of depression and anxiety in a prospective community study: the Zurich Cohort Study. Arch Gen Psychiatry. 2003;60:993-1000

18. Rherbergen D, Batelaan NM, de Graaf R, Nolen WA, Spijker J, Beekman AT, et al. The 7-year course of depression and anxiety in the general population. Acta Psychiatr Scand. 2011;123:297-306.

19. Hendriks SM, Spijker J, Licht CMM, Beekman ATF, Penninx BWJH. Two-year course of anxiety disorders: different across disorders or dimensions? Acta Psychiatr Scand. 2013;128:212-21.

20. Hendriks SM, Spijker J, Licht CMM, Beekman ATF, Hardeveld F, de Graaf R, et al. Long-term work disability and absenteeism in anxiety and depressive disorders. J Affect Disord. 2015;178:121-30.

21. Iancu SC, Batelaan NM, Zweekhorst MBM, Bunders JFG, Veltman DJ, Penninx $\mathrm{BWJH}$, et al. Functional recovery after remission from anxiety disorders. Twoyear course and predictors. Psychol Med. 2014:44:593-605.

22. Bruce SE, Yonkers KA, Otto MW, Eisen JL, Weisberg RB, Pagano M, et al. Influence of psychiatric comorbidity on recovery and recurrence in generalized anxiety disorder, social phobia, and panic disorder: A 12-year prospective study. Am J Psychiatry. 2005;162:1179-87.

23. Keller MB. Social anxiety disorder clinical course and outcome: review of Harvard/Brown Anxiety Research Project (HARP) findings. J Clin Psychiatry. 2006:67:4-19.

24. Batelaan NM, Rhebergen D, Spinhoven P, van Balkom AJ, Penninx BW. Twoyear course trajectories of anxiety disorders: do DSM classifications matter? J Clin Psychiatry. 2014;75:985-93.

25. Penninx BWJH, Nolen WA, Lamers F, Zitman FG, Smit JH, Spinhoven P, et al. Two-year course of depressive and anxiety disorders: results from the Netherlands Study of Depression and Anxiety (NESDA). J Affect Disord. 2011;133:76-85.

26. Penninx BWJH, Beekman ATF, Smit JH, Zitman FG, Nolen WA, Spinhoven PH et al. The Netherlands Study of Depression and Anxiety (NESDA): rationale, objectives and methods. Int J Methods Psychiatr Res. 2008;17:121-40.

27. Wittchen HU. Reliability and validity studies of the WHO-Composite International Diagnostic Interview (CIDI): a critical review. J Psychiatr Res. 1994;28:57-84.

28. Beck AT, Epstein N, Brown G, Steer RA. An inventory for measuring clinical anxiety: psychometric properties. J Consult of Clin Psychol. 1988;56:893-7.

29. Marks IM, Mathews AM. Brief standard self-rating for phobic patients. Behav Res Ther. 1979;17:263-7.

30. Fydrich T, Dowdall D, Chambles DL. Reliability and validity of the Beck Anxiety Inventory. J Anxiety Disord. 1992;6:55-61.

31. Van Zuuren FJ. The fear questionnaire. Some data on validity, reliability and layout. Br J Psychiatry. 1988;153:659-2.

32. World Health Organization. Disability Assessment Schedule II. Geneva: World Health Organization; 2000.

33. Ansseau J, Fischler B, Dierick M, Albert A, Leyman S, Mignon A. Socioeconomics correlates of generalized anxiety disorder and major depression in primary care: the GADIS II study (generalized Anxiety and Depression Impact Survey II). Depress Anxiety. 2008:25:506-13.

34. Roy-Byrne PP, Davidson KW, Kessler RC, Asmundson GJG, Goodwin RD, Kubzansky L, et al. Anxiety disorders and comorbid medical illness. Gen Hosp Psychiatry. 2006;30:208-25.

35. Twisk JWR. Inleiding in de toegepaste biostatistiek. Maarssen: Elsevier Gezondheidszorg; 2007.

36. Stein MB, Kean YM. Disability and quality of life in social phobia: epidemiologic findings. Am J Psychiatry. 2000;157:1606-13.

37. Lochner C, Mogotsi M, du Toit PL, Kaminer D, Niehaus DJ, Stein DJ, et al. Quality of life in anxiety disorders: a comparison of obsessive-compulsive disorder, social anxiety disorder, and panic disorder. Psychopathology. 2003:36:255-62.

38. Bruce SE, Mahan JT, Dyck I, Keller MB. Infrequency of "pure" GAD: impact of psychiatric comorbidity on clinical course. Depress Anxiety. 2001;14:219-25.

39. Kessler RC, Nelson CB, McGonagle KA, Liu J, Swartz M, Blazer DG. Comorbidity of DSM-III-R major depressive disorder in the general population: results from the US National Comorbidity Survey. Br J Psychiatry 1996;30(l):17-30. 
40. Kessler RC, Chiu WT, Demler O, Walters EE. Prevalence, severity, and comorbidity of twelve-month DSM-IV disorders in the National Comorbidity Survey Replication (NCS-R). Arch Gen Psychiatry. 2005;62:617-27.

41. Kessler RC, Gruber M, Hettema JM, Hwang I, Sampson N, Yonkers KA. Comorbid major depression and generalized anxiety disorders in the National Comorbidity Survey follow-up. Psychol Med. 2008;38:365-74.

42. Weisberg RB, Beard C, Pagano ME, Maki KM, Culpepper L, Keller MB. Impairment and functioning in a sample of primary care patients with generalized anxiety disorder: results from the primary care anxiety project. Prim Care Companion J Clin Psychiatry 2010;12.

43. Karsten J, Penninx BW, Verboom CE, Nolen WA, Hartman CA. Course and risk factors of functional impairment in subtreshold depression and anxiety. Depress Anxiety. 2013;30:386-94.

44. Rai D, Skapinakis P, Wiles N, Lewis G, Araya R. Common mental disorders, subthreshold symptoms and disability: longitudinal study. Br J Psychiatry. 2010;197:411-2.

Submit your next manuscript to BioMed Central and we will help you at every step:

- We accept pre-submission inquiries

- Our selector tool helps you to find the most relevant journal

- We provide round the clock customer support

- Convenient online submission

- Thorough peer review

- Inclusion in PubMed and all major indexing services

- Maximum visibility for your research

Submit your manuscript at www.biomedcentral.com/submit
Biomed Central 